\title{
Glifo para Verificação da Utilização de Processos de Requisitos por meio da Rastreabilidade como apoio à Melhoria de Qualidade de Software
}

\begin{abstract}
The requirements management process is very important to software quality assurance. To know what activities are not being properly executed is a way to know about the quality of the process deployment. This paper proposes an approach for visual verification of requirements process by using glyphs. The verification will be supported by traceability techniques.
\end{abstract}

Resumo. O processo de gerência de requisitos é fator determinante para a garantia da qualidade do software. Saber as atividades do processo que não estão sendo realizadas é importante para determinar uma implantação mais consistente do processo. Este artigo propõe a utilização de glifo para visualização da utilização de processos de requisitos. A verificação da utilização de processos será realizada por meio da rastreabilidade bidirecional.

\section{Introdução}

A qualidade de um software é objetivo buscado pelas empresas desenvolvedoras. $\mathrm{O}$ mercado exige softwares com maior qualidade. A falta de qualidade é consequiência de diversos fatores, entre outros, [Pfleeger, 2004]: requisitos incompletos; falta de envolvimento por parte dos usuários; modificações nos requisitos e nas especificações.

Esses fatores estão diretamente ligados ao tratamento inadequado dos requisitos do software e poderiam ser minimizados se existisse uma engenharia de requisitos consistente e atuante do início ao final do projeto, garantindo que o que foi especificado tenha sido corretamente implementado.

Outra forma de minimização destes fatores é a definição de um processo de desenvolvimento de software e a sua implantação na organização, verificando se os projetos da organização estão realmente utilizando todo o processo e se cada atividade do processo está sendo executada ao longo do desenvolvimento. 
A verificação e avaliação da implementação desses requisitos podem ser realizadas a partir de mecanismos que utilizam a rastreabilidade [Cruz et. al. 2006]. Técnicas de rastreabilidade possibilitam mapear um requisito a partir de um ponto inicial até um ponto qualquer de um processo de desenvolvimento, possibilitando ao desenvolvedor verificar se o requisito foi ou não cumprido.

Neste trabalho, é apresentada uma proposta de verificação de utilização de processos de gestão de requisitos por meio do mecanismo de rastreabilidade dos requisitos, com a finalidade de identificar inconsistências e problemas de utilização do processo. A ideia básica consiste em criar uma estrutura de rastreamento para o processo planejado e compará-la com uma outra estrutura de rastreamento do projeto executado. Como forma de visualização dos resultados, é utilizada uma figura chamada glifo que vai permitir visualizar de forma gráfica os pontos problemáticos.

Este artigo está organizado em seis seções. Na seção 2, é apresentada a rastreabilidade e na seção 3 apresenta-se a forma como a rastreabilidade de requisitos pode ser trabalhada para verificação da utilização de um processo de gestão de requisitos. A seção 4 apresenta a visualização de resultados por meio do glifo. Na seção 5 tem-se o estudo de caso mostrando os resultados alcançados; nele é descrito o processo especificado a partir do MPS.BR e de um questionário aplicado em empresas mineiras. A seção 6 mostra os principais resultados da pesquisa, suas contribuições e os trabalhos a serem desenvolvidos no futuro.

\section{Rastreabilidade}

Segundo o guia de implementação do MPS.BR, o conceito de rastreabilidade é "o grau em que o relacionamento pode ser estabelecido entre dois ou mais produtos do desenvolvimento de software" [Softex 2007].

A rastreabilidade, no que tange a requisitos, permite: verificar a origem de cada requisito; verificar os requisitos deriváveis de um requisito específico; determinar os produtos de trabalho que cada requisito gerou; determinar a partir de um produto de trabalho, quais são os requisitos fontes, ou seja, quais são os requisitos que o geraram; e verificar quais são as atividades do processo executadas pelo projeto.

A rastreabilidade de um produto pode ser criada de forma horizontal ou vertical. A horizontal se preocupa com a associação dos requisitos e outros itens do processo. Já a vertical preocupa-se com a decomposição que um requisito pode assumir, ela permite a navegação entre o requisito fonte e seus requisitos de mais baixo nível [Softex 2007], mostrando a relação de dependência entre os diversos requisitos [Pleeger 2004].

Pode-se obter ainda a rastreabilidade para frente e para trás. A para trás procura determinar a origem de cada requisito ou produto de trabalho. A para frente possibilita determinar os produtos de trabalho que serão especificados por cada requisito, ou seja, os produtos de trabalho gerados por cada requisito [Paula Filho 2003]. Realizando a rastreabilidade para frente e para trás, obtém-se a rastreabilidade bidirecional.

Utilizando-se a rastreabilidade bidirecional, é possível determinar se os requisitos especificados foram completamente atendidos e se os requisitos de baixo nível podem ser rastreados [Softex 2007]. 


\section{Verificação de Utilização de Processo por meio da Rastreabilidade}

Nesta sessão é descrita a primeira parte da proposta deste artigo. A ideia se baseia em que, para desenvolver um sistema com qualidade, é necessário utilizar um processo de desenvolvimento de software determinado pela organização. $O$ processo é composto por diversas fases (F1...Fn) que são realizadas por diversas atividades (A1...An) ao longo do ciclo de vida do software, como pode ser visto na Figura 1(a):

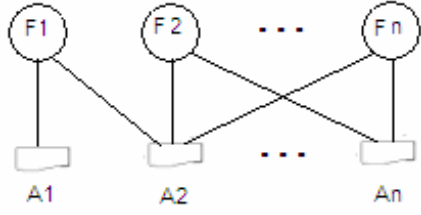

(a)

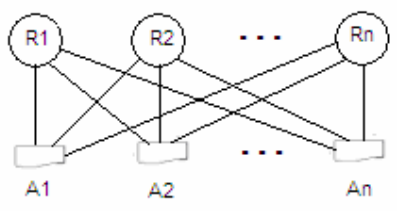

(b)

Figura 1. Processo de Desenvolvimento e Atividades sendo realizadas para o Desenvolvimento dos Requisitos

Estas atividades estão implementando, em diversos níveis de abstração, os requisitos, ou seja, cada requisito vai ser realizado pela execução das diversas atividades determinadas pelo processo de desenvolvimento, conforme apresentado na Figura 1(b).

O objetivo é conseguir determinar quais foram as atividades executadas para atender aos requisitos e realizar a comparação entre as atividades determinadas no processo especificado e geradas pelo projeto executado, de forma a verificar a real utilização do processo. A partir da rastreabilidade horizontal é possível saber se um requisito gerou as atividades necessárias. Com isso, consegue-se saber se ele utilizou o processo de desenvolvimento, de acordo com as atividades que cada requisito gerou. Busca-se, através da rastreabilidade de requisitos, definir se o processo foi utilizado.

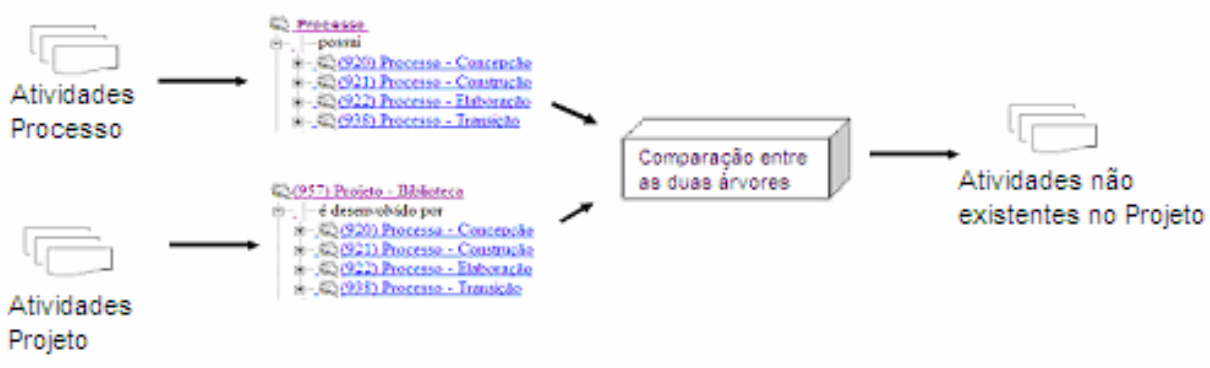

Figura 2. Processo de Verificação por meio da Rastreabilidade

Na Figura 2, que é um esquema que apresenta a idéia, a rastreabilidade é apresentada em forma de árvore, possuindo duas árvores: uma representando o processo definido e outra o projeto executado de acordo com o processo. Comparando as duas árvores, é possível determinar se o requisito foi ou não cumprido, se ele foi implementado conforme especificado. A rastreabilidade deverá ser realizada da forma mais completa possível, deve-se apresentar todas as relações existentes entre os elementos que estão sendo mapeados.

Desta forma, é possível saber quais requisitos chegaram ao final do processo, por quais fases ou atividades do processo ele passou e quais artefatos foram gerados por 
cada um deles. Pela comparação da rastreabilidade, pode-se verificar, então, se este requisito passou por todo o processo estabelecido para o desenvolvimento do sistema.

\subsection{Estensão da Ferramenta para Verificação da Utilização de Processos}

Para auxiliar a construção da rastreabilidade, devem ser utilizadas ferramentas de apoio, facilitando a definição e manutenção. A ferramenta utilizada para auxílio a esta pesquisa é a DBML (Desenvolvimento Baseado em Metas e Léxico), desenvolvida em [Mello Junior 2007], estendida para os propósitos desse trabalho. Ela utiliza o desenvolvimento baseado em metas e a rastreabilidade é conseguida pela utilização do léxico estendido, que é de fácil descrição, pois se assemelha à linguagem natural utilizada pelas pessoas [Mello Junior 2007; Mello Junior et. al. 2007].

O léxico estendido é uma linguagem formada pelos elementos: sujeito, verbo, objeto e estado. De acordo com [Mello Junior 2007], a rastreabilidade é a associação entre elementos. Utilizando o léxico estendido, pode-se realizar essa ligação por meio dos elementos do léxico de cada requisito. O requisito é descrito conforme a estrutura informada pelo léxico estendido.

A partir dessa formação, é possível criar a navegação entre os diversos elementos do léxico, possibilitando que a rastreabilidade possa ser alcançada bidirecionalmente. Para isto, a DBML utiliza os conceitos de composição, voz ativa e voz passiva.

A composição possibilita a ligação entre os diversos elementos do léxico que formam cada um dos requisitos. A composição é representada a partir de uma árvore (Figura 3), onde é possível visualizar a ligação entre os diversos elementos do léxico, ou seja, o sujeito é relacionado com os diversos objetos existentes (é composto pelos objetos) por meio de verbos que realizam esta ligação (por exemplo, possui) [Mello Junior 2007; Mello Junior et. al. 2007].

A apresentação dos dados em uma árvore possibilita a navegação entre os diversos elementos pertencentes ao projeto que está sendo desenvolvido, sendo possível detectar tanto as ligações entre os diversos requisitos quanto as atividades e documentos gerados a partir dos requisitos.

A representação bidirecional é realizada pela utilização da voz ativa e da voz passiva: a voz ativa representa a rastreabilidade para frente e a voz passiva para trás [Mello Junior 2007; Mello Junior et. al. 2007]. Pode-se visualizar essa representação na Figura 3.

Na DBML não havia a distinção entre processo e projeto, desta forma, foi necessário criar uma estrutura que possibilitasse a entrada do processo especificado. A ferramenta foi estendida, possibilitando a entrada do processo da mesma forma que ocorre com o projeto, criando léxicos para cada fase, atividade ou artefato do processo.
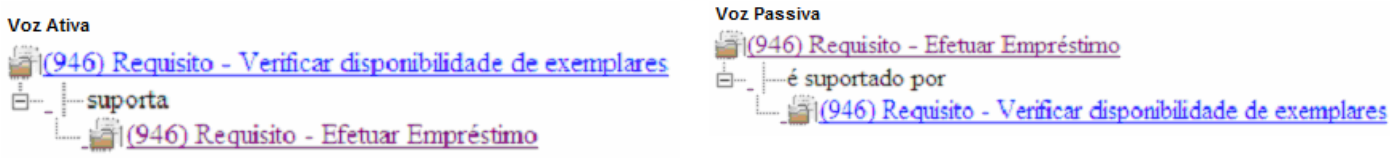

Figura 3. Rastreabilidade na voz ativa e passiva 
Como o processo de gestão de requisitos, as atividades, os requisitos e demais elementos são todos léxicos, é possível mapear os léxicos que representam os elementos semelhantes, possibilitando o mapeamento da existência ou não de um elemento em um projeto.

A partir do projeto construído segundo um processo, com as atividades executadas e a rastreabilidade montada, tanto para o processo quanto para o projeto, é possível navegar pelas árvores verificando os requisitos, as atividades e documentos que foram construídos. Foi desenvolvido um método na ferramenta, que tem o objetivo de comparar as árvores do projeto e do processo definido. Este método realiza uma navegação nas duas árvores através dos léxicos gerados. À medida que vai navegando na árvore do processo e na do projeto, ele vai comparando as atividades e fases executadas. Cada diferença é armazenada em uma lista para posterior apresentação.

Com isso, a partir de um processo inserido no sistema, pode-se comparar se um projeto realizou todas as atividades ou tarefas especificadas no processo e determinar se um requisito, por exemplo, passou por todo um processo de engenharia de requisitos e realizou todas as tarefas necessárias ao seu desenvolvimento.

\section{Visualização por meio de Glifo}

Conforme apresentado na seção anterior, a rastreabilidade possibilita a verificação da utilização de um processo por um projeto, mas os resultados devem ser apresentados de forma a possibilitar uma compreensão e análise mais apurada dos dados, completando a proposta desse trabalho. Assim, optou-se por usar recursos de visualização de dados. Como o propósito do projeto Discovery [Pietrobon 2007], ao qual este trabalho está inserido, é a facilidade de visualização dos dados, o glifo borboleta foi utilizado com esse fim.

A visualização é responsável por apresentar os dados em imagens com a finalidade de mostrar mais claramente as informações. As imagens ajudam na assimilação da informação, pois o ser humano tem a capacidade de apreender o conteúdo das imagens mais facilmente do que as informações textuais [Carmo, 2002].

Um aspecto importante a ser considerado para a apresentação de informações é a forma como ela é organizada e visualizada [Carmo 2002]. É importante que toda, ou grande parte da informação necessária seja apresentada de uma forma que possa ser avaliada em conjunto, permitindo ao usuário ter uma visão global do que ele esta analisando, no caso, o processo de software.

Segundo [Colturato 2001], para que os dados possam ser visualizados, antes devem ser tratados e organizados de alguma forma. Sem essa organização, é impossível apresentar os resultados necessários. Aqui, utiliza-se a rastreabilidade, da forma descrita na seção 3 para organizar esses dados.

Para a apresentação de diversas informações ao mesmo tempo, propõe-se utilizar um glifo. Um glifo é uma figura onde cada parte pode significar, representar uma informação diferente, possibilitando a visualização de diversos atributos do problema ao mesmo tempo. Além disso, ele é uma estrutura dinâmica que modifica a sua aparência de acordo com alterações dos atributos exibidos [Mendonça 2001]. 
O glifo desenvolvido tem a forma de uma borboleta (Figura 4). Conforme pode ser visto, ele possui nove partes ou áreas de informação. As informações apresentadas em cada parte são determinadas pelo usuário do sistema que pode utilizar todas as partes ou não. O glifo pode ser estruturado para cada projeto específico e para um projeto podem ser configurados mais de um glifo.

Cada uma das partes da borboleta receberá um valor de acordo com o atributo de processo analisado, ou seja, cada parte determinará, a partir da rastreabilidade, um valor que possibilitará saber se o processo foi ou não seguido conforme o especificado pela organização.

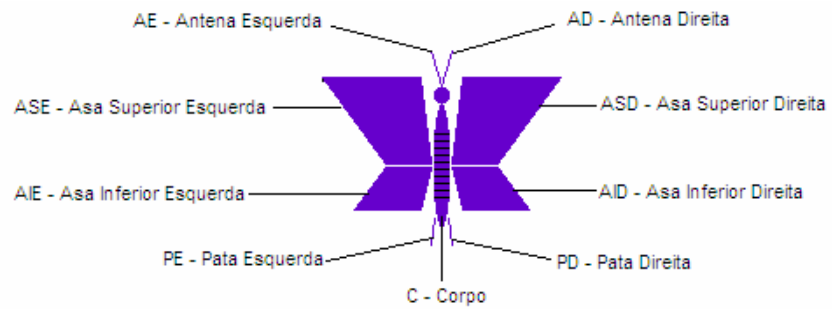

Figura 4. Glifo borboleta

O glifo apresentado na Figura 4 representa a situação ideal, ou seja, o que deveria ocorrer no caso de o projeto seguir completamente todo o processo definido. $\mathrm{O}$ glifo que mostra um projeto que não utilizou todo o processo definido, ou seja, que não executou todas as atividades necessárias, conforme o processo estabelecido, possui variações em suas partes, deformações no desenho.

A vantagem da utilização do glifo é a rapidez da percepção dos problemas encontrados, apenas observando a imagem pode-se perceber o que está e o que não está de acordo com o modelo determinado. Com esse resultado, é possível, caso seja necessário, realizar uma análise mais detalhada do projeto, estudar a rastreabilidade ou verificar outros glifos para chegar à conclusão de quais são as falhas existentes no projeto construído.

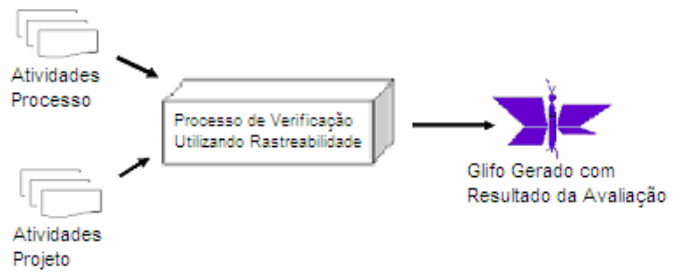

Figura 5. Esquema do Processo de Verificação Gerando o Glifo.

O esquema apresentado na figura 5 é o modelo de trabalho. Conforme pode ser observado, existem diversas atividades necessárias ao processo e existem as atividades que o projeto executou de acordo com o processo. O processo de verificação utilizando a rastreabilidade possibilita a comparação dessas atividades e a saída da verificação será um glifo borboleta mostrando a situação do projeto que foi avaliado. É importante salientar que, só é realizada a verificação da existência da atividade, sem validar se ela está correta. 


\subsection{Estensão da Ferramenta para Inserção do Glifo}

Para a visualização dos dados por meio do glifo foi necessário inicialmente criar uma classe para o desenho do glifo. Esta classe possibilita que a borboleta seja gerada. Ela foi construída de forma a permitir que sejam passados os parâmetros para o desenho das partes da borboleta. Para as asas, antenas e patas, deve ser passado uma porcentagem e para o corpo um valor que varia de 0 a 10 (zero a dez).

Para tornar o sistema mais flexível e possibilitar a interligação do componente gerado com a ferramenta DBML, foi necessário criar uma funcionalidade no sistema que permitisse a definição dos parâmetros a serem definidos para cada parte da borboleta.

Foi gerada uma tela para definição dos itens da borboleta a serem considerados. É necessário definir um nome para o glifo e para cada uma das partes da borboleta, fazendo uma associação com os léxicos que ele representa no processo definido. Existe uma associação de cada parte com as fases e/ou atividades que ela representa.

Foi necessário criar uma forma de passar os valores para cada parte, com isso, um método foi gerado para possibilitar que os dados recuperados da rastreabilidade pudessem ser mapeados para as partes da borboleta. Esse método tem a responsabilidade de passar os parâmetros para que a borboleta possa ser gerada. Ele realiza um cálculo que apresenta o resultado que cada parte deverá possuir. Isso é realizado devido ao léxico utilizado para a configuração do glifo ser o mesmo utilizado para a definição do processo e para a entrada do projeto.

O método verifica, a partir da lista de diferenças entre processo e projeto gerada na rastreabilidade, a porcentagem que cada elemento da borboleta deverá possuir. Este cálculo só é possível, pois existe um mapeamento de todos os elementos que a parte deve representar, sabendo-se que este valor comporta $100 \%$ (cem por cento) e, caso seja encontrado algum problema, basta fazer a correlação para descobrir o valor que será apresentado no glifo.

A estensão foi realizada de tal forma a possibilitar que, no momento da geração do léxico, possa ser escolhido não só o glifo (mapeamento) desejado, como também a parte do projeto a analisar. Com isso, é possível analisar um único requisito, diversos requisitos ou até mesmo mais de um projeto.

A partir das respostas obtidas do glifo, uma análise mais apurada dos dados pode ser realizada. Para isso, é possível, selecionar para cada parte, um novo glifo ou a visualização da árvore de rastreabilidade. O novo glifo selecionado pode ser do mesmo tipo do anterior apenas com um conjunto de requisitos diferente, ou um novo tipo de glifo que possui associação com os léxicos da parte que esta sendo analisada.

Uma característica importante é que a classe glifo foi desenvolvida de forma a permitir a sua utilização em outras ferramentas ou análise de outros problemas, sendo um componente que pode ser configurado de acordo com o problema e ferramenta escolhido.

\section{Estudo de Caso}




\subsection{Processo de Requisitos segundo o MPS.BR e as Empresas Mineiras}

Para o desenvolvimento do estudo de caso, foi necessário desenvolver um processo. A escolha foi por um processo de gestão de requisitos. Como a qualidade é um dos atributos perseguidos por este trabalho, optou-se por construir um processo baseado no MR-MPS e no que algumas empresas mineiras, que estão trabalhando para alcançar a certificação MPS.BR, estão trabalhando.

Como a preocupação principal deste estudo de caso é o processo de requisitos de software, observou-se a forma como o MR-MPS trata a gestão de requisitos. Já para obter os dados das empresas mineiras, optou-se pela distribuição de um questionário com o objetivo principal de levantar dados a respeito da engenharia de requisitos realizada pelas diversas organizações de desenvolvimento de software. Os questionários foram distribuídos pelo CCOMP / FUMSOFT, sendo respondidos por nove empresas.

O processo de gestão de requisitos utilizado para realização do estudo de caso é baseado no processo unificado, tendo as fases: concepção, elaboração, construção e transição. As atividades de cada fase, considerando a gestão de requisitos, são:

- Concepção - definição de escopo do projeto; definição de lista de requisitos; definição de restrições; verificação de viabilidade; definição do cronograma do projeto; definição de métricas para avaliação e controle dos requisitos; alinhamento da 'regra do jogo' com usuário; alinhamento técnico dos analistas de negócio e de requisitos; validação dos requisitos junto ao usuário;

- Elaboração - criação da rastreabilidade; descrição dos requisitos do sistema; criação dos casos de uso do sistema; detalhamento por meio de casos de uso e descrição dos casos de uso; aprovação dos requisitos; checklist, questionários, entrevistas, cenários e observações; análise de impacto das alterações; documentação de alterações solicitadas; aprovação das alterações de requisitos;

- Construção - desenvolvimento do sistema de acordo com os requisitos especificados; teste do sistema; verificação por pares; correções necessárias;

- Transição - verificação dos requisitos; validação dos requisitos junto ao usuário; aceite do cliente.

\subsection{Estudo de Caso Biblioteca}

Para realização do estudo de caso, será apresentada a análise de um módulo de um sistema de biblioteca com os seguintes requisitos: cadastrar livro; cadastrar autor; cadastrar usuário da biblioteca; cadastrar exemplar; efetuar empréstimo; efetuar devolução; cadastrar editora; efetuar reserva.

Quando se inicia um projeto, deve-se cadastrar o processo, o projeto e montar a rastreabilidade. A primeira parte necessária é a definição do processo padrão, ou seja, do processo de gestão de requisitos que será utilizado pelo sistema.

Após realizar esses cadastros, a rastreabilidade está montada e é possível fazer as análises de rastreabilidade e de utilização do processo. O glifo é utilizado para apresentar os resultados. Para a definição dos glifos a serem utilizados outro cadastro deve ser gerado, associando-o ao projeto e definindo os léxicos relacionados a cada parte da borboleta gerada. 
A primeira borboleta definida foi criada para a análise de cada fase do processo, sendo que, para cada uma das fases é apresentada a porcentagem que indica as atividades que foram realizadas na fase especificada (Figura 6). As partes da borboleta foram definidas da seguinte forma: ASE - Concepção; ASD - Elaboração; AIE Construção; AID - Transição; Demais partes - não consideradas.

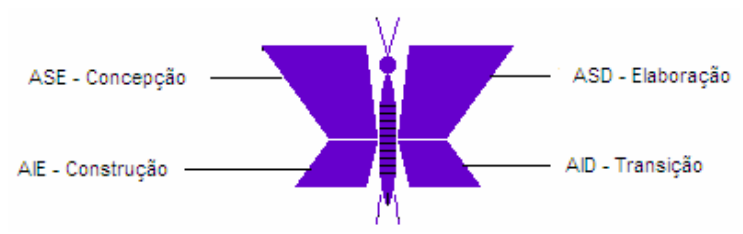

Figura 6: Glifo Borboleta 1 - Fases do Processo

A segunda borboleta apresenta as atividades da fase concepção para a análise a ser realizada (Figura 7). As partes definidas foram: ASE - Definir escopo projeto; ASD - Definir lista Requisitos; AIE - Definir Restrições; AID - Definir Cronograma Projeto; AE - Alinhar "Regra do Jogo" com usuário; AD - Alinhar tecnicamente analistas negócio e requisitos; PD - Validar requisitos junto ao usuário; PE - Definir Etapas do Projeto; C - Definir Listas de Entrega.

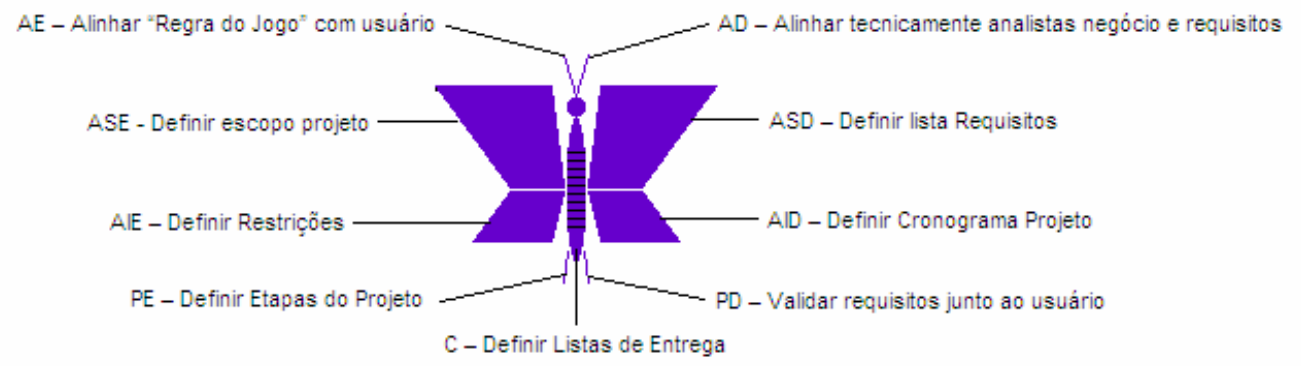

Figura 7: Glifo Borboleta 2 - Atividades da Concepção

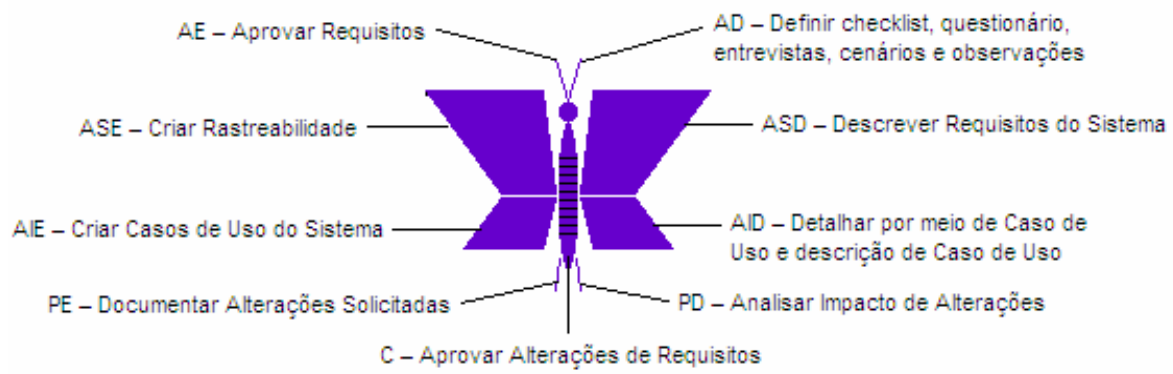

Figura 8: Glifo Borboleta 3 - Atividades da Elaboração

A terceira borboleta apresenta as atividades da fase de elaboração (Figura 8). Suas partes são: ASE - Criar Rastreabilidade; ASD - Descrever Requisitos do Sistema; AIE - Criar Casos de Uso do Sistema; AID - Detalhar por meio de Caso de Uso e descrição de Caso de Uso; AE - Aprovar Requisitos; AD - Definir checklist, questionário, entrevistas, cenários e observações; PD - Analisar Impacto de Alterações; PE - Documentar Alterações Solicitadas; C - Aprovar Alterações de Requisitos 
A quarta borboleta apresenta as atividades da construção (Figura 9). Suas partes são: ASE - Desenvolver Sistema; ASD - Testar Sistema; AIE - Verificar em pares; AID - Realizar Correções; Demais partes - não consideradas.

A quinta borboleta apresenta as atividades da fase de transição (Figura 10). Suas partes são: ASE - Validar Requisitos junto ao usuário; ASD - Realizar aceite do cliente; Demais partes - não consideradas.

As borboletas apresentadas aqui são utilizadas para a verificação da utilização do processo e é necessária a seleção do processo e do projeto que serão comparados. A análise pode ser realizada para um conjunto de requisitos definidos, podendo ser selecionado um ou mais requisitos do projeto.

O primeiro glifo apresenta uma situação geral do projeto, mostrando a situação de todas as atividades de cada uma das fases. As outras quatro borboletas mostram a situação dos artefatos e templates de cada uma das fases separadamente. A Figura 11a mostra a situação ideal do projeto para a análise de fases, todas as atividades são executadas em cada uma das fases do projeto.

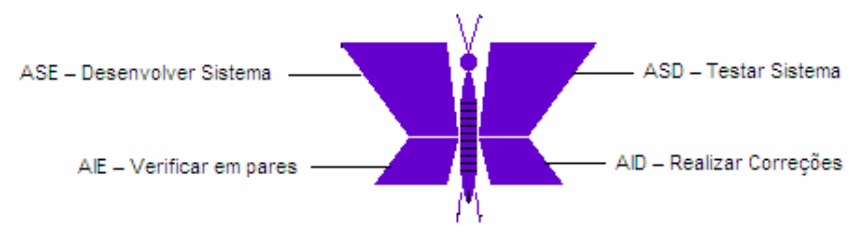

Figura 9: Glifo Borboleta 4 - Atividades da Construção

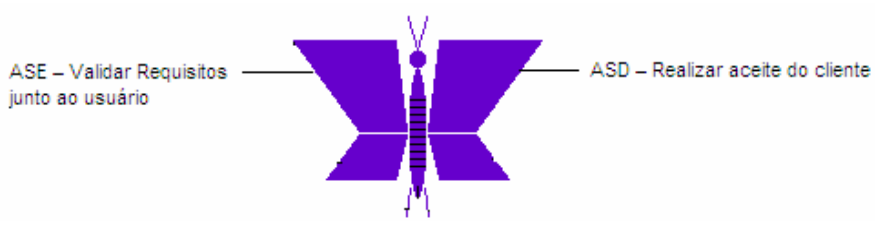

Figura 10: Glifo Borboleta 5 - Atividades da Transição

Ao selecionar o projeto biblioteca criado e selecionar todos os requisitos do sistema, observa-se que as atividades não foram todas realizadas, sendo apresentado o glifo borboleta da Figura 11b.

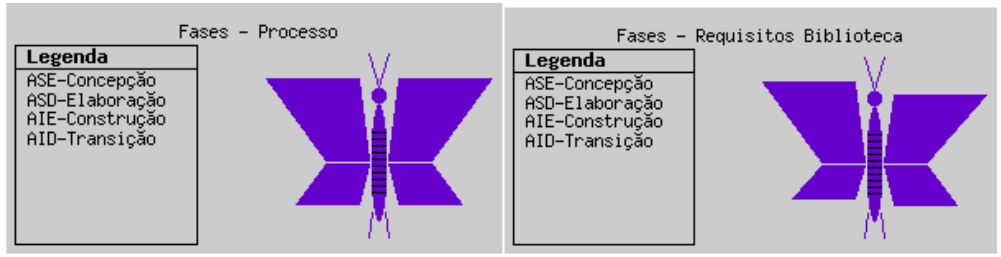

Figura 11: a) Borboleta 1 - Fases do Processo - Situação Ideal e b) Borboleta 1 - Fases do Processo - Situação do Projeto Biblioteca

As fases de elaboração e construção não foram completamente realizadas e pode-se observar isso pela deformação existente na asa superior direita e na asa inferior esquerda da borboleta. Observa-se, também, que a deformação encontrada é pequena em 
relação ao que idealmente deveria ser efetuado, demonstrando que algumas poucas atividades do processo não foram efetuadas em alguns requisitos do sistema.

É necessário, a partir daí, realizar uma análise mais aprofundada do sistema, podendo ser geradas outras borboletas ou a navegação pela árvore de rastreabilidade do sistema. As novas borboletas geradas podem tanto detalhar a apresentada, entrando nas fases que tiveram problemas para conseguir avaliar quais artefatos não foram gerados, até realizando a seleção de um número reduzido de requisitos para avaliação.

Separando-se os requisitos em dois grupos, um que mostra todos os requisitos de cadastro do sistema e outro que avalia os demais requisitos do sistema, têm-se as borboletas das Figuras 12 (a e b).

Ao observar as duas borboletas geradas, percebe-se que nos dois grupos continuam a existir problemas com a execução das atividades pelos requisitos, mas a borboleta de cadastros obteve maior deformação nas asas, mostrando que a não utilização do processo ocorreu principalmente neste tipo de requisito.

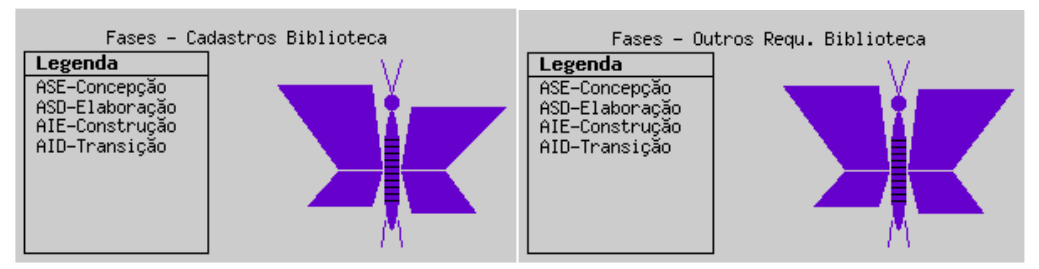

\section{Figura 12: a) Glifo Borboleta 1 - Requisitos Cadastro Biblioteca e b) Glifo Borboleta 1 - Demais Requisitos Biblioteca}

Realizando-se uma análise mais aprofundada, foi observado que os requisitos que possuem problema na utilização do processo são: Cadastrar Usuário da Biblioteca; Cadastrar Editora; Cadastrar Autor e Pesquisar Livro. Os demais requisitos do sistema utilizaram o processo completamente. Foi, então, desenvolvido um glifo que apresenta a situação desses requisitos que não utilizaram o processo completamente (Figura 13a).

Após a realização destas análises, tinham-se duas opções: ou se fazia a análise da árvore de rastreabilidade do sistema ou das borboletas que detalham cada uma das fases, para observar quais artefatos foram afetados.

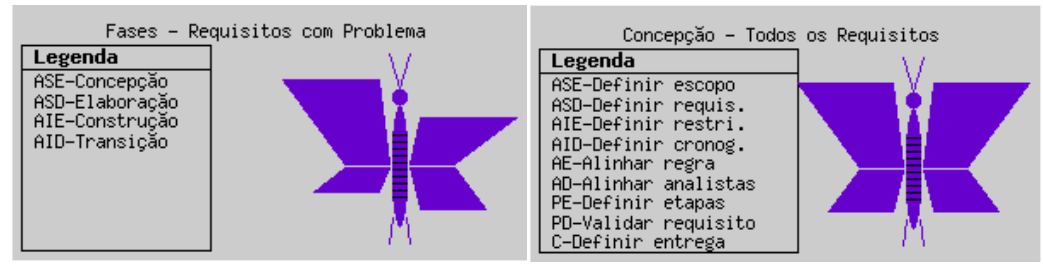

Figura 13: a) Glifo Borboleta 1 - Requisitos com Problema e b) Glifo Borboleta 2 - Fase Concepção - Todos os Requisitos

Inicialmente, foram geradas as borboletas das fases de concepção e transição. Apesar do projeto biblioteca não ter obtido problemas nessas duas fases, era interessante observar se mesmo com as atividades sendo realizadas, algum artefato do sistema não foi criado. Foi observado que as duas fases tiveram todos os artefatos gerados, sendo apresentadas as borboletas das Figuras 13b e 14a. 
Após essas análises, era necessário criar as borboletas para as fases de elaboração e transição para observar quais artefatos não foram criados em cada atividade. A Figura 14b mostra a borboleta da fase de elaboração.

Conforme pode ser observado apenas as atividades "Criar Casos de Uso do Sistema"; "Aprovar Requisitos" e "Aprovar Alterações de Requisitos" possuem todos os artefatos criados, as demais atividades tiveram problemas na criação de artefatos. É interessante, então, fazer uma análise mais detalhada para determinar os requisitos que não possuem algum artefato criado.

Como realizado anteriormente, os requisitos foram separados em dois grupos, um com os requisitos de cadastro e outro com os demais requisitos (Figura 15a e b).

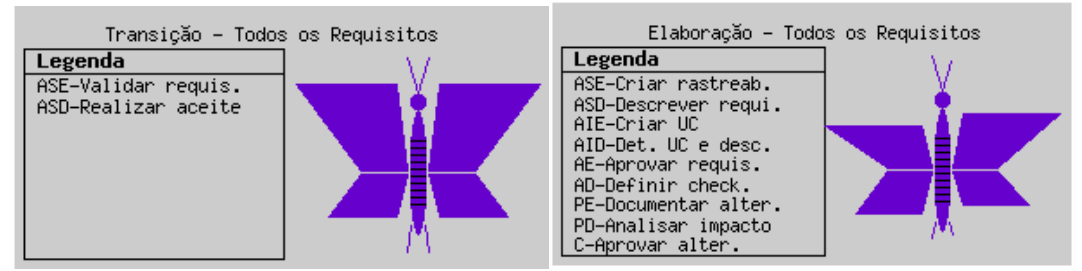

\section{Figura 14: a) Glifo Borboleta 5 - Fase Transição - Todos os Requisitos e b) Glifo Borboleta 3 - Fase Elaboração - Todos os Requisitos}

Observando-se as duas figuras, verifica-se que, da mesma forma que ocorreu na análise das fases, os cadastros obtiveram maior influência na não utilização do processo de gestão de requisitos especificado. Um fato que chama a atenção é que a atividade "Criar Rastreabilidade" nas duas borboletas têm a mesma deformação. Ao analisar as fases, observou-se que nas borboletas do processo, a fase de elaboração obteve uma grande diferenciação de uma fase para outra (Figuras 12a e b).

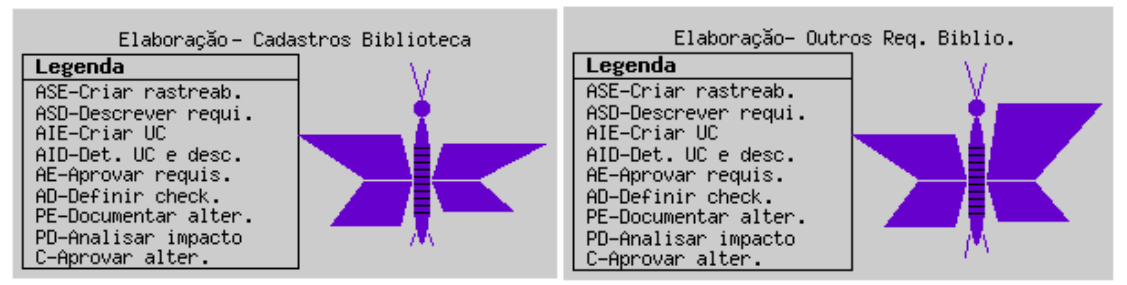

\section{Figura 15: a) Glifo Borboleta 3 - Fase Elaboração - Cadastros Biblioteca e b) Glifo Borboleta 3 - Fase Elaboração - Demais Requisitos Biblioteca}

Como isso chamou a atenção, foram analisados os requisitos separadamente, de forma a identificar os problemas e foi verificado que todos os requisitos tiveram problema na atividade "Criar Rastreabilidade", já que o artefato "Matriz requisitos funcionais X casos de uso" não foi construído para nenhum dos requisitos do sistema. Essa análise foi realizada, inicialmente gerando individualmente as borboletas de cada requisito separadamente e foi observado que em todas as borboletas geradas, ocorreram deformações na asa superior esquerda que representa a atividade "Criar Rastreabilidade".

Foi analisada também a árvore de rastreabilidade, sendo observado que o artefato "Matriz requisitos funcionais X casos de uso" não foi encontrado em nenhum 
dos requisitos A Figura 16 mostra uma parte da árvore de rastreabilidade do projeto biblioteca, na qual isso pode ser observado.

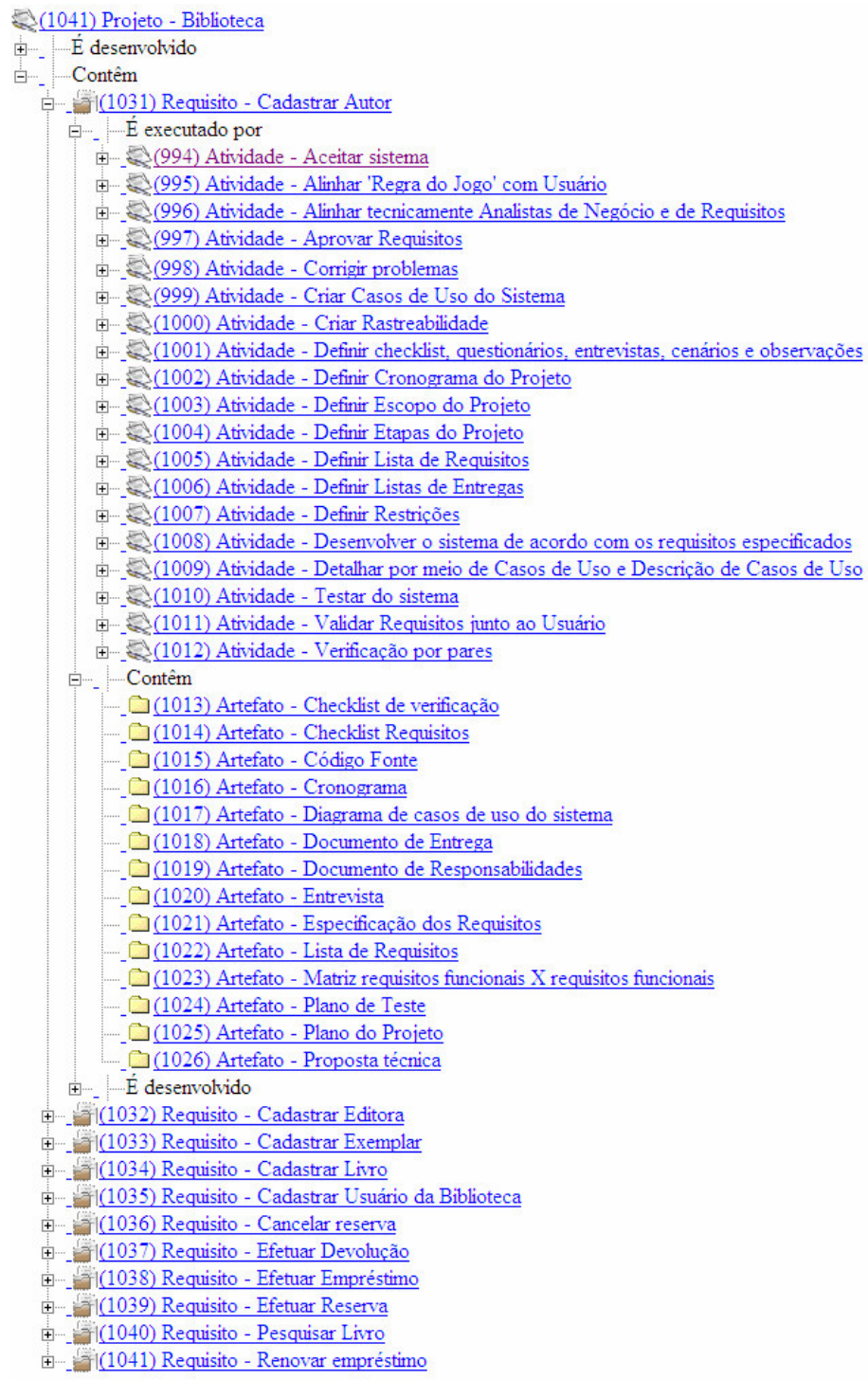

Figura 16: Árvore de Rastreabilidade mostrando Detalhes do Requisito Cadastrar Autor

A árvore apresenta todos os requisitos do projeto biblioteca, com o requisito "Cadastrar Autor" detalhado. Para esse requisito, são apresentadas as suas atividades e os seus artefatos. Pode-se observar que o requisito "Cadastrar Autor" efetuou a atividade "Criar Rastreabilidade" e não possui o artefato "Matriz requisitos funcionais X casos de uso".

$\mathrm{Na}$ fase de construção, foi desenvolvida uma borboleta que apresenta todos os requisitos do sistema (Figura 17a). Apenas os artefatos da atividade "Desenvolver Sistema" foram todos criados. As demais atividades não tiveram todos os artefatos criados. Foram desenvolvidas, conforme ocorreu nos demais casos, uma borboleta que apresenta os requisitos de cadastro e outra com os demais requisitos (Figuras 17b e 18a). 


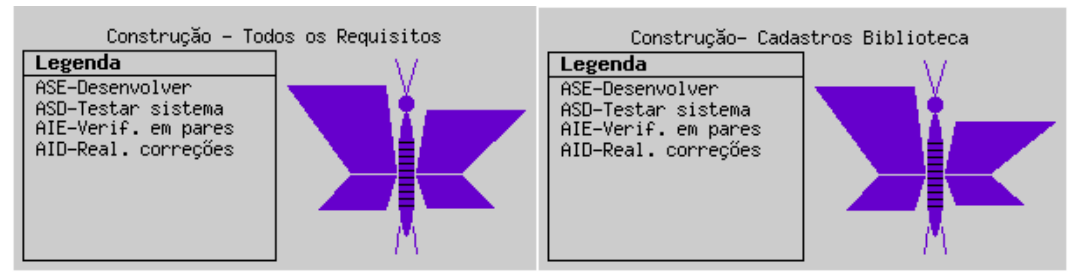

Figura 17: a) Glifo Borboleta 4 - Fase Construção - Todos os Requisitos e b) FIGURA 1: Glifo Borboleta 4 - Fase Construção - Requisitos Cadastro

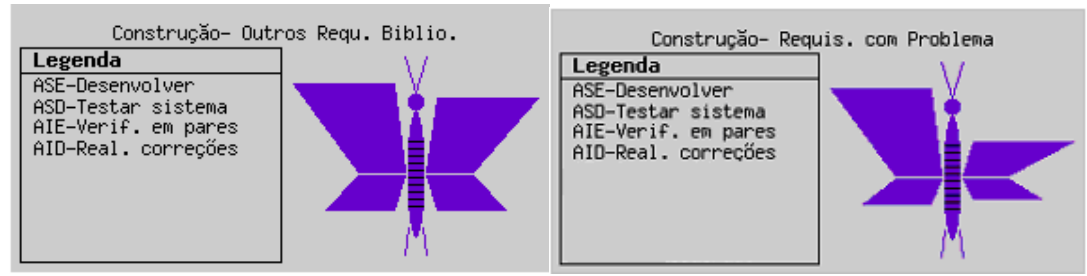

Figura 18: a) Glifo Borboleta 4 - Fase Construção - Demais Requisitos Biblioteca e b) Glifo Borboleta 4 - Fase Construção - Requisitos com Problema

Realizando demais análises, tanto em relação à geração de glifos quanto verificando as árvores de rastreabilidade, observa-se que os requisitos que causam problema na fase de construção são: Cadastrar Usuário da biblioteca; Cadastrar Editora; Cadastrar Autor; Cadastrar Livro; Pesquisar Livro. Foi desenvolvida uma borboleta apenas com esses requisitos (Figura 18b).

\section{Conclusão}

Este trabalho apresentou uma forma de comparar o projeto especificado com o processo utilizado para seu desenvolvimento por meio da rastreabilidade, apresentando os resultados referentes à utilização real do processo por meio de glifo e árvore de rastreabilidade.

Verifica-se que o glifo auxilia bastante o avaliador, possibilitando que ele, numa análise rápida, tire conclusões a respeito da situação dos projetos em relação ao processo utilizado. Necessitando de mais detalhes, ele pode verificar pela própria ferramenta, utilizando a árvore de rastreabilidade quais são os pontos que não estão de acordo, facilitando o trabalho de investigação de problemas em processos.

Esta pesquisa apóia a melhoria de qualidade e a equipe de qualidade da organização, uma vez que fornece uma ferramenta que possibilita a análise rápida de processos e de melhorias a serem realizadas nesses processos. No estudo de caso, foi apresentado um processo de gestão de requisitos, mas nada impede de ser utilizado um processo de desenvolvimento completo.

A comunidade entende a importância da rastreabilidade, mas não utiliza todo o poder de informação que ela pode gerar. Esta pesquisa procurou especificar uma forma de utilizar a rastreabilidade no nível gerencial e não apenas no nível de desenvolvimento. O maior problema dessa solução é conseguir manter a rastreabilidade completa dos requisitos do sistema, até o nível de artefatos, mas essa mesma dificuldade já é encontrada quando se utiliza a rastreabilidade para verificar a alteração de requisitos. 
As normas de qualidade estabelecem que a rastreabilidade deve ser mantida para todos os projetos. Como ela já deverá ser mantida, para se adequar às normas, é interessante que a organização passe a não só utilizá-la para a verificação de impacto, mas para trazer outros benefícios, compensando o seu esforço de construção.

As maiores contribuições da pesquisa são: verificação da importância da rastreabilidade de software para o desenvolvimento de software; melhoria de processos de software com apoio da análise de rastreabilidade; utilização de glifos para visualização de resultados multivariados.

Como trabalhos futuros, pode-se citar: incrementar o glifo, possibilitando que com a seleção dos seus elementos, seja possível obter detalhes a respeito da parte selecionada; verificação da aderência de projetos a modelos; utilização do glifo borboleta para análise de outros elementos da engenharia de software e, finalmente, generalização do editor de glifo para que outros glifos possam ser criados.

\section{Referências}

Carmo, M.B. (2002) "Visualização de Informação Modelo Integrado para o Tratamento de Filtragem e Múltiplas Representações”. Tese de Doutorado, Departamento de Informática da Faculdade de Ciências da Universidade de Lisboa, Portugal.

Colturato, D.B. (2001) "Ambiente Interativo para Visualização de Dados de Neurônios”. Dissertação de Mestrado. Universidade de São Paulo.

Cruz, J.L.; Jino, M.; Crespo, A.N.; Argollo, M. (2006) "Suporte automatizado à rastreabilidade em um processo de teste de software baseado em documentação". V Simpósio Brasileiro de Qualidade de Software, SBQS.

Mello Junior, F.C. (2007) "Proposta de utilização de metas e rastreabilidade baseada em léxico estendido para manipulação do conhecimento em uma pequena empresa". Dissertação de Mestrado. PUC-MG. Belo Horizonte, Minas Gerais.

Mello Junior, F.C.; Guedes, F.C.; Pinheiro, C. A. dos S.; Pietrobon, C. A. M. (2007) "DBML - Ferramenta de Rastreabilidade Baseada em Metas e Léxico". SBES2007 Simpósio Brasileiro de Engenharia de Software. Sessão de Ferramentas

Mendonça, M.B. (2001) "Aplicação de Texturas em Visualização Científica". Dissertação de Mestrado. Instituto de Ciências Matemáticas e de Computação. Universidade de São Paulo.

Paula Filho, W.P. (2003) "Engenharia de Software: Fundamentos, Métodos e Padrões". 2 ed. RJ: LTC.

Pfleeger, S.L. (2004) "Engenharia de Software: teoria e prática”. 2 ed. SP: Prentice Hall.

Pietrobon, C.A.M. (2007) "Projeto Discovery”. Relatório Técnico, RT 01/2007, PPGEE.

Softex. (2007) "Guia de Implementação MPS.BR - Parte 1 V1.1" http://www.softex.br/mpsbr/_guias/MPS.BR_Guia_de_Implementacao_Parte_1_V1. 1.pdf. 